\title{
TUTELAS DE URGÊNCIA E OS DIREITOS FUNDAMENTAIS SOB A VISÃO CONSTITUCIONAL DO PROCESSO CIVIL ${ }^{1}$
}

IMMEDIATE INJUNCTIONS AND FUNDAMENTAL RIGHTS UNDER A CONSTITUTIONAL VIEW OF CIVIL PROCEDURE

Renata Cristina Faria OLIVER ${ }^{2}$

ISSUE DOI: $10.21207 / 2675-0104.2018 .726$

\begin{abstract}
RESUMO
O presente trabalho tem como objeto central o estudo dos direitos fundamentais e das tutelas de urgência em face dos princípios do prazo razoável e do contraditório, e como são conceituadas as medidas cautelares e antecipatórias, bem quais são suas destinações e aplicabilidade frente ao direito processual civil, sempre ponderando sobre a efetividade do provimento jurisdicional em razão da morosidade da justiça. Na pesquisa foi utilizado o método hipotético-dedutivo, que se desenvolve de modo investigativo com levantamento de informações constantes em livros, legislação e jurisprudência. A pesquisa demonstra a importância da ponderação quanto a efetividade do provimento jurisdicional face a longa duração do processo e como as tutelas de urgência podem ser manejadas a fim de resguardar o direito tutelado ou antecipar o os efeitos da tutela, sem que tais medidas afrontem os princípios fundamentais e o contraditório, buscando a eficácia e celeridade processual.
\end{abstract}

Palavras-chave: direitos fundamentais, tutelas de urgência, princípios constitucionais.

\section{ABSTRACT}

The main objective of this study is to study fundamental rights and urgent protection in the light of the principles of reasonable and contradictory time and how precautionary and anticipatory measures are considered, as well as their destinations and applicability to civil procedural law, always pondering on the effectiveness of the jurisdictional provision due to the length of justice. In the research was used

\footnotetext{
${ }^{1} \mathrm{O}$ presente artigo sintetiza a monografia de conclusão da pesquisa, realizada para o Programa Interno de Bolsas de Iniciação Científica (PIBIC 2017-2018) da Faculdade de Direito de Franca (FDF), Franca/SP.

${ }^{2}$ Discente da Faculdade de Direito de Franca (FDF), Franca/SP. Bolsista do Programa Interno de Bolsas de Iniciação Científica (PIBIC 2017-2018).
} 
the hypothetical-deductive method, which is developed in an investigative way with the collection of information in books, legislation and jurisprudence. The research demonstrates the importance of weighing the effectiveness of the jurisdictional provision in the face of the long duration of the process and how the urgency treaties can be managed in order to protect the protected right or anticipate the effects of the guardianship, without such measures affording the principles contradictory, seeking efficiency and speed of procedure.

Keywords: fundamental rights, emergency guardianships, constitutional principles.

\section{INTRODUÇÃO}

O presente artigo tem como objetivo analisar uma das grandes problemáticas processuais, a morosidade do provimento judicial, não são raras às vezes em que ocorre o perecimento do direito material em face da demora da decisão judicial, tornando sem efetividade a tutela jurisdicional.

Nesse diapasão entra em cena a denominada tutela de urgência, que tem por objetivo, de modo geral, acelerar e efetivar a resposta jurisdicional desejada, afastando as degradantes e indesejadas consequências que o fator temporal pode causar ao processo.

A visão constitucional do processo civil se refere a observância dos princípios constitucionais aplicáveis ao longo do processo, em especial da duração razoável do processo e do contraditório e ampla defesa, princípios ligados as tutelas de urgência e a efetividade da prestação jurisdicional.

O presente trabalho analisa a temática dos direitos fundamentais e das tutelas de urgência na perspectiva da efetividade do processo sob a luz da moderna visão constitucional do processo civil, abordando a hermenêutica da ponderação de valores.

Em decorrência dos riscos da longa duração do processo, há mecanismos de atuação processual para mitigá-los, a entrega da tutela definitiva pode surgir após trâmite lento, com desprestígio da efetividade.

Nesse sentido houve a incorporação no sistema processual de mecanismos para a proteção da urgência. São eles temporários e propiciam a garantia da utilidade da atuação jurisdicional futura e definitiva ou a própria antecipação do bem da vida tutelado, respectivamente, tutela cautelar e tutela antecipada, tais instrumentos processuais são denominados de tutela de urgência.

Assim, o presente artigo pretende esclarecer os critérios adequados de utilização das tutelas de urgência sob a luz constitucional do processo civil em face dos princípios do prazo razoável e do contraditório, especificando noções gerais, natureza jurídica. O objetivo geral é 
compreender a efetividade dos direitos fundamentais frente aos princípios constitucionais.

\section{DIREITOS FUNDAMENTAIS}

A Constituição de 1988 pautada no princípio da dignidade da pessoa humana, fundamento da República Federativa do Brasil, elenca um amplo rol de direitos fundamentais com o objetivo de assegurar aos cidadãos uma vida digna e controlar os abusos do poder estatal. São bens indisponíveis, imprescritíveis e insuscetíveis de alienação. A conceituação de direitos fundamentais está ligada a ideia dos direitos básicos de qualquer humano, positivados na esfera constitucional do Estado.

A fim de conceituar direitos fundamentais temos a definição dada por João Trindade 3 :

(...) poderíamos definir os direitos fundamentais como os direitos considerados básicos para qualquer ser humano, independentemente de condições pessoais específicas. São direitos que compõem um núcleo intangível de direitos dos seres humanos submetidos a uma determinada ordem jurídica.

Nota-se, portanto, que os direitos fundamentais são direitos básicos do ser humano, positivados na esfera constitucional do Estado, garantindo a obrigatoriedade do Estado em assegurar aos cidadãos um padrão de vida digno.

Nesse sentido podemos citar Clémerson Merlin Cléve: ${ }^{4}$

Todos os poderes do Estado, ou melhor, todos os órgãos constitucionais, têm por finalidade buscar a plena satisfação dos direitos fundamentais. Quando o Estado se desvia ele está, do ponto de vista político, se deslegitimando, e do ponto de vista jurídico, se desconstitucionalizando - é isso que nós precisamos ter em mente. (...) Assim, podemos dizer que a Constituição Federal define alguns aspectos e retira do debate político uma série de outros. Ela, que tem uma dimensão política, tem outra dimensão que é despolitizadora, quer dizer, isto que está definido politicamente a partir de agora é direito e, como questões nucleares, estão e haverão

${ }^{3}$ CAVAlCANTE FILHO, João trindade. Teoria geral dos direitos fundamentais. Disponível em: http://www.stf.jus.br/repositorio/cms/portalTvJustica/portalTvJusticaNoticia/anexo/Joao_Trindadade Teoria_Geral_dos_direitos_fundamentais.pdf Acesso em: 05/09/2017.

${ }^{4}$ CLÉVE, Clémerson Merlin. O Controle da Constitucionalidade e a Efetividade dos Direitos Fundamentais in Jurisdição Constitucional e Direitos Fundamentais. Belo Horizonte: Del Rey. 2003. P. 388/389. 
de estar fora do debate político, porque são princípios fundamentais, porque são objetivos fundamentais, por que são cláusulas pétreas ou por que são direitos fundamentais. O papel da política, nesta circunstância, é decidir "o como", porque "o que" já está definido pela Constituição.

É possível concluir que a conceituação dos direitos fundamentais está ligada ao princípio da dignidade, direitos básicos de qualquer ser humano, onde não há quaisquer condições pessoais específicas e cuja efetividade não depende apenas de sua previsão normativa, mas também de ações concretas do Poder Público.

Atualmente a doutrina classifica os direitos fundamentais em primeira, segunda e terceira gerações, baseando-se na ordem cronológica que passaram a ser reconhecidos, bem como a natureza que possuem.

Colaborando com esse entendimento podemos citar Celso de Mello5:

\begin{abstract}
Enquanto os direitos de primeira geração (direitos civis e políticos) que compreendem as liberdades clássicas, negativas ou formais realçam o princípio da liberdade e os direitos de segunda geração (direitos econômicos, sociais e culturais) - que se identificam com as liberdades positivas, reais ou concretas - acentuam o princípio da igualdade, os direitos de terceira geração, que materializam poderes de titularidade coletiva atribuídos genericamente a todas as formações sociais, consagram o princípio da solidariedade e constituem um momento importante no processo de desenvolvimento, expansão e reconhecimento dos direitos humanos, caracterizados enquanto valores fundamentais indisponíveis, pela nota de uma essencial inexauribilidade.
\end{abstract}

Cada geração se deu de forma gradativa, evoluindo e acumulando direitos, como os direitos fundamentais foram conquistados, as diferentes gerações se complementam, sendo importante uma breve explanação sobre cada uma delas.

Os direitos fundamentais da primeira geração surgiram com a Revolução Francesa, entre os séculos XVIII e XIX, constituindo os chamados direitos individuais ou negativos, inspirados pelo Estado Liberal. Durante essa fase ocorreu o reconhecimento dos direitos civis e políticos, como por exemplo, o direito à liberdade, igualdade, propriedade privada, entre outros.

Nesse contexto elucida Ingo Sarlet ${ }^{6}$ :

${ }^{5}$ MELLO FILHO, José Celso. Constituição Federal anotada. 2. ed. São Paulo: Saraiva.1986.

${ }^{6}$ SARLET, Ingo Wolfgang. A eficácia dos direitos fundamentais. Porto Alegre: Livraria do Advogado. 1998. p. 48. 
Os direitos fundamentais, ao menos no âmbito de seu reconhecimento nas primeiras Constituições escritas, são o produto peculiar (ressalvado certo conteúdo social característico do constitucionalismo Francês), do pensamento liberal-burguês do século XVIII, de marcado cunho individualista, surgindo e afirmando-se como direitos do indivíduo frente ao Estado, mais especificamente como direitos de defesa, demarcando uma zona de não-intervenção do Estado e uma esfera de autonomia individual em face de seu poder. São, por este motivo, apresentados como direitos de cunho "negativo", uma vez que dirigidos a uma abstenção, e não a uma conduta positiva por parte dos poderes públicos, sendo, neste sentido, "direitos de resistência ou de oposição perante o Estado".

Tais direitos são os primeiros a serem previstos em lei na fase inicial do constitucionalismo e estão arrolados em todas as constituições dos estados democráticos.

A segunda geração dos direitos fundamentais está atrelada aos princípios do Estado Social, reivindicando do poder estatal ações que garantam condições mínimas de dignidade à população atribuindo ao Estado um comportamento ativo com as prestações sociais estatais, reconhecendo os direitos sociais, econômicos e culturais.

Conforme destaca Sarlet ${ }^{7}$, tal geração está ligada às manifestações em busca da redução das desigualdades.

O impacto da industrialização e os graves problemas sociais e econômicos que a acompanharam, as doutrinas socialistas e a constatação de que a consagração formal de liberdade e igualdade não gerava a garantia do seu efetivo gozo acabaram, já no decorrer do século XIX, gerando amplos movimentos reivindicatórios e o reconhecimento progressivo de direitos atribuindo ao Estado comportamento ativo na realização da justiça social. A nota distintiva destes direitos a sua dimensão positiva, uma vez que se cuida não mais de evitar a intervenção do Estado na esfera da liberdade individual, mas, sim, na lapidar formulação de C. Lafer, de propiciar um "direito de participar do bem estar social". Não se cuida mais, portanto, de liberdade do e perante o Estado, e sim de liberdade por intermédio do Estado.

Nessa nova geração, o Estado passa a exercer uma atuação positiva em benefício da coletividade, de forma a garantir a igualdade entre os cidadãos, sendo chamada essa geração de direitos de igualdade, pois busca diminuir as desigualdades sociais.

${ }^{7}$ SARLET, Ingo Wolfgang. A eficácia dos direitos fundamentais. Porto Alegre: Livraria do Advogado. 1998, p. 49/50. 
Com a revolução tecnológica e científica advinda da terceira revolução industrial, aflora nos cidadãos a necessidade de proteger a coletividade, com o objetivo de proteção aos direitos difusos e coletivos ocorre a terceira geração dos direitos fundamentais, chamados de direitos de solidariedade e fraternidade.

Como bem leciona Gilmar Ferreira Mendes, Inocêncio Mártires Coelho e Paulo Gustavo Gonet Branco ${ }^{8}$ :

Já os direitos chamados de terceira geração peculiariza-se pela titularidade difusa ou coletiva, uma vez que são concebidos para a proteção não do homem isoladamente, mas da coletividade, de grupos. Tem-se, aqui, o direito à paz, ao desenvolvimento, à qualidade do meio ambiente, à conservação do patrimônio histórico

e cultural.

Os direitos difusos são aqueles direitos de todos, que não pertencem a ninguém isoladamente, destaca-se como exemplos de direitos fundamentais da terceira geração o direito ao desenvolvimento, a um meio ambiente equilibrado, direito ao patrimônio comum da humanidade, direito à paz, entre outros.

Atualmente existem doutrinadores que defendem a existência dos direitos fundamentais da quarta geração, que se refere à manipulação genética, à biotecnologia e à bioengenharia. Esses direitos são frutos da constante transformação que a sociedade vive, surgindo com o intuito de preencher as necessidades da sociedade.

Nesse sentido podemos citar Paulo Bonavides ${ }^{9}$ que defende a existência de tais direitos:

A globalização política neoliberal caminha silenciosa, sem nenhuma referência de valores. (...) Há, contudo, outra globalização política, que ora se desenvolve, sobre a qual não tem jurisdição a ideologia neoliberal. Radica-se na teoria dos direitos fundamentais. A única verdadeiramente que interessa aos povos da periferia. Globalizar direitos fundamentais equivale a universalizálos no campo institucional. (...) A globalização política na esfera da normatividade jurídica introduz os direitos de quarta geração, que, aliás, correspondem à derradeira fase de institucionalização do Estado social. É direito de quarta geração o direito à democracia, o direito à informação e o direito ao pluralismo. Deles depende a concretização da sociedade aberta do futuro, em sua dimensão de

\footnotetext{
${ }^{8}$ MENDES, Gilmar Ferreira; COELHO, Inocêncio Mártires; BRANCO, Paulo Gustavo Gonet. Curso de direito constitucional. 2. ed. São Paulo: Saraiva. 2008.p. 234.

${ }^{9}$ BONAVIDES, Paulo. Curso de Direito Constitucional. 26. ed. atual. São Paulo: Malheiros. 2011. p. 571-572.
} 
máxima universalidade, para a qual parece o mundo inclinar-se no plano de todas as relações de convivência. (...) os direitos da primeira geração, direitos individuais, os da segunda, direitos sociais, e os da terceira, direitos ao desenvolvimento, ao meio ambiente, à paz e à fraternidade, permanecem eficazes, são infraestruturais, formam a pirâmide cujo ápice é o direito à democracia.

Conclui-se que os direitos fundamentais são resultados de lutas e reivindicações sociais, sendo que a divisão em gerações retrata apenas o enaltecimento de determinados direitos em momentos distintos. Os direitos fundamentais de todas as gerações são o alicerce das sociedades democráticas.

\section{DAS TUTELAS DE URGÊNCIA NO NOVO CÓDIGO DE PROCESSO CIVIL}

\subsection{TUTELA DE URGÊNCIA}

O Código de Processo Civil de 2015 elenca como espécie das Tutelas Provisórias as Tutelas de Evidência e as Tutelas de Urgência, tema do presente estudo, a qual merece destaque e explanações a respeito de suas características e subespécies.

A demora do provimento judicial é certamente uma das grandes problemáticas processuais, e é neste contexto que as tutelas de urgência estão inseridas com intuito claro de dar celeridade ao direito tutelado.

O deferimento de uma tutela de urgência é realizado pelo magistrado por meio de uma cognição sumária, através de técnicas antecipatórias ou assecuratórias, tendo em vista a necessidade de uma tutela imediata.

Nesse contexto podemos citar Eduardo Lamy ${ }^{10}$ :

Portanto, a tutela de urgência corresponde ao resultado rápido que a jurisdição, através do processo, não pode deixar de atingir em muitas e frequentes situações do cotidiano. Trata-se do gênero da tutela que se destina a evitar danos oriundos da demora da prestação jurisdicional, ou da necessidade existente, conforme a natureza do direito material protegido, de obter-se o pronunciamento

${ }^{10}$ LAMY, Eduardo. Tutela Provisória. São Paulo: Atlas. 2018. P. 49 
jurisdicional antes do exaurimento da cognição, para que a prestação jurisdicional seja tempestiva e efetiva.

O fundamento da referida tutela está definido no caráter urgente da demanda, de forma que a demora do provimento jurisdicional poderia ocasionar dano ao direito material, colocando em risco a efetividade do processo. Desse modo, se mostra uma técnica processual indispensável ao ordenamento jurídico brasileiro.

Colaborando com tal entendimento podemos citar Bedaque ${ }^{11}$ :

O longo tempo exigido para a entrega de uma tutela definitiva, antecedida de amplo contraditório e cognição exauriente, vem se mostrando absolutamente incompatível com as necessidades do mundo moderno. Esse problema se agrava em países como o Brasil, onde fatores extraprocessuais acabam contribuindo para retardar ainda mais o resultado do processo, tornando a demora fenômeno anormal e insuportável.

Portanto, esse procedimento objetiva impedir a ocorrência de um dano grave ou irreparável durante o processo, o que ocasionaria a inefetividade da jurisdição. A tutela de urgência está prevista no artigo 300 do $\mathrm{CPC}$ e possui alguns requisitos, a seguir expostos:

Art. 300. A tutela de urgência será concedida quando houver elementos que evidenciem a probabilidade do direito e o perigo de dano ou o risco ao resultado útil do processo.

A tutela de urgência antecipada ou cautelar pressupõe a demonstração da probabilidade do direito (fumus boni iuris) e do perigo da demora (periculum in mora), sendo concedida quando preenchidos os requisitos do artigo 300 do CPC.

A probabilidade do direito significa a presença de fundamentos que tornem verossímil o direito em litígio, devendo o magistrado analisar se há informações que colaborem com a probabilidade de existência do direito e quais as chances de resultados da demanda.

De acordo com Fredie Didier ${ }^{12}$ :

A probabilidade do direito a ser provisoriamente satisfeito/realizado ou acautelado é a plausibilidade de existência

\footnotetext{
${ }^{11}$ BEDAQUE, José Roberto dos Santos. Direito e processo: influência do direito material sobre o processo. Tutela Cautelar e tutela antecipada: tutelas sumárias e de urgência. São Paulo: Saraiva. 1998. P. 193

${ }^{12}$ DIDIER JR., Fredie. Curso de direito processual civil.Vol.2. ed.12. Salvador: JusPodivm. P. 675
} 
desse mesmo direito. O bem conhecido fumus boni iuris (ou fumaça do bom direito).

O magistrado precisa avaliar se há "elementos que evidenciem" a probabilidade de ter acontecido o que foi narrado e quais as chances de êxito do demandante (art. 300, CPC).

Além disto, o deferimento somente é autorizado quando a demora do provimento jurisdicional causar um dano de difícil reversibilidade ou irreversível. Além disso, o dano deve ser não hipotético e concreto, atual ou na iminência de ocorrer e grave, que possa prejudicar a fruição do direito.

Nesse sentido aduz Carneiro ${ }^{13}$ :

Enfim, o deferimento da tutela provisória somente se justifica quando não for possível aguardar pelo término do processo para entregar a tutela jurisdicional, porque a demora do processo pode causar à parte um dano irreversível ou de difícil reversibilidade.

Após as considerações gerais sobre as tutelas provisórias de urgência, é necessário o esclarecimento a respeito de suas subespécies, a Tutela Cautelar e Tutela Antecipada.

As medidas cautelares possuem como objetivo eliminar ou mitigar os riscos inerentes ao perecimento do direito discutido no âmbito da ação principal. Com elas busca-se assegurar as condições necessárias para a futura eficácia da tutela definitiva.

No atual Código, a técnica cautelar não é mais executada por meio do chamado processo cautelar, como antes era previsto no Código de Processo Civil de 1973. A previsão legal das medidas cautelares encontrase no artigo 301 do Código de Processo Civil, possuindo como principal função assegurar o resultado do processo, de modo que a decisão final possa ser efetivada. A seguir o referido artigo:

Art. 301. A tutela de urgência de natureza cautelar pode ser efetivada mediante arresto, seqüestro, arrolamento de bens, registro

\footnotetext{
${ }^{13}$ CARNEIRO, Athos Gusmão. Da antecipação de tutela. $5^{\text {a }}$ ed. São Paulo: Saraiva. 2004. P. 31
} 
de protesto contra alienação de bem e qualquer outra medida idônea para asseguração do direito.

Nesse sentido leciona Lamy ${ }^{14}$ :

\begin{abstract}
A técnica cautelar é aquela que objetiva assegurar o resultado útil da demanda principal a qual é apenas acessória. A noção de cautela liga-se à ideia de garantia do bem jurídico objeto da outra ação. Por isso mesmo, o provimento urgente, oriundo de técnica cautelar propriamente dita, sempre se refere a uma demanda - outra principal, possuindo as características primordiais da referibilidade e acessoriedade.
\end{abstract}

Isto posto, fica evidente que o objetivo da cautelar é assegurar a efetividade da tutela contra a violação do direito ou eventual dano decorrente da demora do julgamento definitivo da lide possa causar, desse modo a tutela cautelar busca proteger o direito e não o processo.

O procedimento para sua concessão está disciplinado nos artigos 305 e seguintes do CPC. O artigo 305 merece destaque por elencar os requisitos da petição inicial:

Art. 305. A petição inicial da ação que visa à prestação de tutela cautelar em caráter antecedente indicará a lide e seu fundamento, a exposição sumária do direito que se objetiva assegurar e o perigo de dano ou o risco ao resultado útil do processo.

Ao deferir a petição inicial o magistrado deverá ordenar o cumprimento da medida bem como determinar a citação do réu para que no prazo de 05 dias possa contestar o pedido, caso o réu não exerça seu direito de manifestar contrariamente ao pedido, fica configurada a revelia e os fatos alegados pelo autor serão considerados como verdadeiros, ocorrendo à decisão definitiva da lide. Caso o réu conteste, o feito prosseguirá pelo procedimento comum, conforme artigo 307 do CPC:

Art. 307. Não sendo contestado o pedido, os fatos alegados pelo autor presumir-se-ão aceitos pelo réu como ocorridos, caso em que o juiz decidirá dentro de 5 (cinco) dias.

Parágrafo único. Contestado o pedido no prazo legal, observar-seá o procedimento comum.

De acordo com o artigo 308 do CPC efetivada a tutela cautelar, o pedido principal terá de ser formulado pelo autor no prazo de 30 (trinta)

${ }^{14}$ LAMY, Eduardo. Tutela Provisória. São Paulo: Atlas. 2018. P. 59 
dias, caso em que será apresentado nos mesmos autos em que deduzido o pedido de tutela cautelar, não dependendo do adiantamento de novas custas processuais.

Nesse sentindo elucida Fredie Didier ${ }^{15}$ :

Promovida, contudo, sua efetivação, com emprego de qualquer medida adequada para tanto (ex: arresto, sequestro, arrolamento de bens e registro de protesto contra alienação de bens), começará a correr prazo de trinta dias para que o autor formule o pedido de tutela definitiva satisfativa (o chamado "pedido principal") e adite a causa de pedir correlata, sob pena de cessação da eficácia da medida cautelar (arts. 308, caput e $\S 2^{\circ}, 309$, I, CPC). O prazo será contado da data em que foi praticado o primeiro ato efetivação da medida. Não se exige o adiantamento de novas custas processuais (art. 308, caput, CPC).

A tutela cautelar, assim como na tutela de urgência, possui dois pressupostos, o fumus boni iuris e o periculum in mora. Tal instituto deve ser aplicado quando houver probabilidade do direito na ação principal, bem como o risco de dano ao bem objeto daquela ação, em razão da demora da prestação jurisdicional.

A tutela antecipada surgiu como forma de antecipar o resultado da sentença, afim de afastar os danos materiais sofridos pelas partes em razão da morosidade processual, tal espécie de tutela é uma antecipação do mérito, concedendo os efeitos da sentença, sendo requerida em um procedimento autônomo dependente do processo principal.

Nesse cenário aduz Didier ${ }^{16}$ a respeito das tutelas antecedentes:

A tutela provisória antecedente foi concebida para aqueles casos em que a situação de urgência já é presente no momento da propositura da ação e, em razão disso, a parte não dispõe de tempo hábil para levantar os elementos necessários para formular o pedido de tutela definitiva (e respectiva causa de pedir) de modo completo e acabado, reservando-se à fazê-lo posteriormente.

\footnotetext{
${ }^{15}$ DIDIER JR., Fredie. Curso de direito processual civil,. Ed.12. Salvador: JusPodivm,. P. 697

${ }^{16}$ DIDIER JR., Fredie. Curso de direito processual civil ed. 12. Salvador: JusPodivm. p. 572
} 
Dessa forma, o magistrado decide de maneira antecipatória o que é pedido ao final da demanda, através da cognição sumária e com base em um juízo de verossimilhança, sendo possível a revogação ou modificação. Tal instituto garante a efetividade do processo que seria afetada em razão da demora de uma cognição exauriente.

Colaborando com esse entendimento podemos citar Sidnei Amendoeira $\mathrm{Jr}{ }^{17} \cdot$ :

A antecipação de tutela é o instituto que se permite ao magistrado antecipar, total ou parcialmente, a tutela pleiteada pelo autor em sua peça inicial e que somente lhe seria concedida ao final do procedimento de primeiro grau, com a sentença de mérito. Trata-se de tutela temporariamente satisfativa. Por ser concedida mediante cognição sumária não é, portanto, definitiva, e sim provisória e revogável.

Portanto, a tutela antecipada deve ser utilizada nos casos em que a situação de urgência já está presente na propositura da petição inicial. A medida possibilita antecipar a satisfação do direito material, de forma que o Estado proporciona uma segurança jurídica aos litigantes que buscam no processo uma forma justa de garantir seus direitos assegurados em lei.

Quanto aos pressupostos da antecipação dos efeitos da tutela o legislador criou os requisitos obrigatórios elencados no artigo 303 do CPC, a seguir:

Art. 303. Nos casos em que a urgência for contemporânea à propositura da ação, a petição inicial pode limitar-se ao requerimento da tutela antecipada e à indicação do pedido de tutela final, com a exposição da lide, do direito que se busca realizar e do perigo de dano ou do risco ao resultado útil do processo.

O legislador exige apenas que haja risco de dano e probabilidade do direito alegado, além da reversibilidade da medida, pois caso seja irreversível levaria a uma decisão definitiva.

Segundo Zavascki ${ }^{18}$ :

É pressuposto indispensável ao deferimento da medida antecipatória, que o direito do autor seja verossímil e fundado em prova inequívoca, assim considerada a que, embora em juízo de cognição sumária, propicie convicção robusta sobre a verdade dos fatos; (...) É indispensável, ademais, a agregação de um dos

\footnotetext{
${ }^{17}$ AMENDOEIRA Jr., Sidnei. Manual de Direito Processual Civil. Teoria geral do Processo e fase de conhecimento em primeiro grau de jurisdição. 2 ed. São Paulo: Saraiva. 2012, . p. 481.

${ }^{18}$ ZAVASCKI, Teori Albino. Antecipação da tutela. São Paulo: Saraiva. 2000 P. 100
} 
seguintes pressupostos: receio de dano irreparável ou de difícil reparação (risco concreto, atual e grave, apto a prejudicar ou fazer perecer, no curso do processo, o direito afirmado pelo autor).

É cauteloso que os efeitos da tutela antecipada sejam reversíveis caso não seja confirmada ao final da lide, de modo que seja viável a devolução do status quo ante as partes, se por acaso for proferida uma sentença de improcedência do pedido do autor.

Nesse sentido elucida Fredie Didier ${ }^{19}$ :

Conceder uma tutela provisória satisfativa irreversível seria conceder a própria tutela definitiva - uma contradição em termos. Equivaleria a antecipar a própria vitória definitiva do autor, sem assegurar ao réu o devido processo legal e o contraditório, cujo exercício "ante a irreversibilidade da situação de fato, tornar-se-ia absolutamente inútil, como inútil seria, nestes casos o prosseguimento do próprio processo".

Ainda sobre a decisão, o Código de Processo Civil inovou ao prever a estabilização da tutela antecipada no artigo 304. Caso não seja proposto recurso, os efeitos da decisão tornaram-se estáveis, entretanto, não gerará coisa julgada material.

CPC:

Tal inovação pode ser analisada no artigo 304, parágrafo $6^{\circ}$ do

Art. 304. A tutela antecipada, concedida nos termos do art. 303, torna-se estável se da decisão que a conceder não for interposto o respectivo recurso.

§ 6o A decisão que concede a tutela não fará coisa julgada, mas a estabilidade dos respectivos efeitos só será afastada por decisão que a revir, reformar ou invalidar, proferida em ação ajuizada por uma das partes, nos termos do $§ 20$ deste artigo.

A estabilização da tutela antecipada não se confunde com a coisa julgada, pois apenas os efeitos da decisão são estabilizados, sem resolução do mérito, de forma que é possível a propositura de ação para reformar, rever ou invalidar a decisão. 


\section{$4 \quad$ DOS DIREITOS FUNDAMENTAIS E TUTELAS DE URGÊNCIA EM FACE DOS PRINCÍPIOS DO PRAZO RAZOÁVEL E DO CONTRADITÓRIO}

Em tempos de incalculáveis relações humanas, não são poucas as vezes que ocorrem o perecimento do direito tutelado, a questão da efetividade do processo é destaque especial como forma de se tentar garantir os direitos fundamentais previstos em nosso ordenamento jurídico. Quando o tema analisado é o processo, obrigatoriamente se fala em tempos e prazos.

Observar-se que o princípio da inafastabilidade da jurisdição deve-se ser interpretado com a visão constitucional do processo civil e não como mera garantia do cidadão, de forma que realmente garanta a efetividade processual buscada pelos litigantes, afastando a visão tradicionalista.

Como bem observa Carlos Alberto Álvaro de Oliveira ${ }^{20}$ :

Cada vez mais nos distanciamos da concepção tradicional, que via os direitos fundamentais, de um modo geral, como singelas garantias. Para o ilustre professor gaúcho, os direitos intitulados fundamentais devem ser vistos como direitos constitutivos institucionais, e não como singelos limitadores defensivos do arbítrio estatal.

Entretanto, o conflito que se observa é que na medida em que se objetiva por meio de uma tutela de urgência uma proteção ao direito pretendido, acaba por mitigar os direitos à segurança jurídica e ao contraditório, de forma que é necessária a busca por um método efetivo de solução de conflitos.

O princípio do contraditório representa à oportunidade dada as partes processuais de se manifestarem a respeito de qualquer ato executado no processo. Para melhor conceituação do princípio esclarece Alexandre de Morais $^{21}$ :

[...] o contraditório é a própria exteriorização da ampla defesa, impondo a condução dialética do processo (par conditio), pois a todo ato produzido pela acusação caberá igual direito da defesa de opor-se-lhe ou de dar-lhe a versão que melhor lhe apresente, ou,

\footnotetext{
${ }^{20}$ OLIVEIRA, Carlos Alberto Alvaro de. O processo civil na perspectiva dos Revista Intertemas Leituras complementares de processo civil. 6. ed. Salvador: Juspodivm, 2008. p. 232.

${ }^{21}$ MORAES, Alexandre de. Direito constitucional, 23 ${ }^{\text {a }}$ Ed.. 2. São Paulo: Atlas. 2008, p. 106.
} 
ainda, de fornecer uma interpretação jurídica diversa daquela feita pelo autor.

Como se observa o princípio do contraditório garante as partes o direito de produzir sua defesa ao longo do processo, como forma de colaborar para o livre convencimento do magistrado.

Entretanto, o princípio do prazo razoável do processo almeja proporcionar as partes um processo eficiente em um tempo útil ao direito, de forma que não ocorra o perecimento, buscando sempre a celeridade da tramitação dos feitos.

Nesse sentido segue os ensinamentos de Gilmar Ferreira Mendes, Inocêncio Mártires Coelho e Paulo Gustavo Gonet Branco ${ }^{22}$ :

\begin{abstract}
O reconhecimento de um direito subjetivo a um processo célere ou com duração razoável - impõe ao Poder Público em geral e ao Poder Judiciário, em particular, a adoção de medidas destinadas a realizar esse objetivo. Nesse cenário, abre-se um campo inconstitucional destinado ao planejamento, controle e fiscalização de políticas públicas de prestação jurisdicional que dizem respeito à própria legitimidade de intervenções estatais que importem, ao menos potencialmente, lesão ou ameaça a direitos fundamentais. $\mathrm{O}$ assunto envolve temas complexos e pretensões variadas, como a modernização e simplificação do sistema processual, a criação de órgãos judiciais em número adequado e a própria modernização e controle da prestação jurisdicional e de questões relacionadas à efetividade do acesso à justiça.
\end{abstract}

Apesar disso, a prestação jurisdicional é morosa, de forma que não ocorre de forma efetiva e útil a solução dos conflitos. Nesse contexto, as tutelas de urgência garantem de maneira efetiva o resultado do direito material tutelado, ou mesmo, que não ocorra o perecimento de tal direito antes do julgamento definitivo da lide.

Podemos concluir que as garantias constitucionais protegem os cidadãos, de forma que são direitos e devem ser exigidas. A garantia do prazo razoável, em virtude de diversos fatores, encontra dificuldades de ser efetiva no judiciário brasileiro, de forma que as tutelas de urgência são garantias para a efetivação do direito material em risco de perecimento. Quanto ao princípio do contraditório observa-se que é vital para a igualdade entre as partes e aplicação da justiça.

\footnotetext{
${ }^{22}$ MENDES, Gilmar Ferreira; COELHO, Inocêncio Mártires; BRANCO. Paulo Gustavo Gonet. Curso de direito constitucional. 2. ed.. São Paulo: Saraiva. 2008. p. 500.
} 
A respeito da colisão dos direitos fundamentais podemos citar Gilmar Ferreira Mendes, Inocêncio Mártires Coelho e Paulo Gustavo Gonet Branco ${ }^{23}$ :

\begin{abstract}
As colisões de direitos fundamentais, bem assim os conflitos desses direitos com outros valores constitucionais, vêm despertando a atenção da mais moderna doutrina. $\mathrm{O}$ assunto se entrelaça com a busca da compreensão do conteúdo e dos lindes dos diferentes direitos fundamentais. Que acontece quando duas posições protegidas como direitos fundamentais diferentes contendem por prevalecer numa mesma situação?
\end{abstract}

Não há uma hierarquização entre os postulados fundamentais, entretanto, podem ocorrer uma eventual relação de prioridades entre eles, como por exemplo, o direito à vida em detrimento do adverso direito da outra parte. Desta forma, ao conceder uma tutela de urgência garantindo o direito fundamental da parte postulante ocorre a limitação de outro direito fundamental da parte contrária.

Nesse sentido elucida José Canotilho ${ }^{24}$ :

[...] considera-se existir uma colisão autêntica de direitos fundamentais quando o exercício de um direito fundamental por parte do seu titular colide com o exercício do direito fundamental por parte de outro titular. Aqui não estamos perante um cruzamento ou acumulação de direitos (como na concorrência de direitos), mas perante um choque, um autêntico conflito de direitos. A colisão de direitos em sentido impróprio tem lugar quando o exercício de um direito fundamental colide com outros bens constitucionalmente protegidos. [...]

Nesse diapasão, o deferimento de uma tutela de urgência gera prejuízos para a parte demandada, uma vez que a princípio ocorre apenas uma cognição sumária, e em razão dessa análise mais superficial a outra parte alcançará seus objetivos. Destaca-se que a concessão poderá ocorrer sem o contraditório, ocasionando um conflito entre direitos fundamentais.

Não há princípio que deva se sobrepor aos demais, devendo ser utilizada a conciliação entre princípios quando houver conflitos, analisando o caso concreto e a relevância de cada direito em oposição.

Dessa forma, as tutelas de urgência mostram-se como mecanismos de atendimento ao princípio do prazo razoável, protegendo e

\footnotetext{
${ }^{23}$ MENDES, Gilmar Ferreira; COELHO, Inocêncio Mártires; BRANCO, Paulo Gustavo Gonet. Curso de direito constitucional. 2. ed.. São Paulo: Saraiva. 2008. p. 283.

${ }^{24}$ CANOTILHO, José Joaquim Gomes. Estudo sobre os Direitos Fundamentais. São Paulo: Saraiva. 2008. p. 1270 .
} 
concretizando um direito fundamental urgente, de forma que não ocorre violação ao princípio do contraditório, uma vez que este será concedido em momento posterior, de forma que não ocorrerá uma decisão definitiva sem o devido contraditório.

Portanto, a arte de sopesar é fundamental para a aplicação dos princípios de acordo com o caso prático em questão, resolvendo-se da melhor forma possível. Por conseguinte, ao lidar com medidas urgentes, direitos e garantias fundamentais deve ser sempre sopesado os dois lados, ou seja, colocado na balança para ver qual se evidencia mais, caso não seja possível à harmonização entre eles.

\section{CONSIDERAÇÕES FINAIS}

Ao longo do presente artigo buscou-se dirimir as controvérsias existentes quanto à utilização das tutelas de urgência para assegurar a uma parte o resultado eficaz do processo ou mesmo para antecipar os efeitos da tutela.

Desta forma, foram abordados os direitos fundamentais como um todo, destacando a classificação dos direitos fundamentais em gerações, demonstrando as características de cada uma delas, observando que apesar das garantias obtidas ainda há muito o que mudar.

Tratou-se das tutelas de urgência, buscando definir seus fundamentos, pressupostos e requisitos legais, destacando as distinções entre medidas cautelares e antecipatórias, trazendo também as previsões legais de ambas medidas, de forma que foi possível destacar a importância e a necessidade da aplicação das tutelas de urgência para proporcionar eficácia da tutela jurisdicional.

Por fim, houve a conceituação dos princípios do prazo razoável e do contraditório, abordando os direitos fundamentais em face de tais princípios, observando também as colisões entre direitos fundamentais e os princípios suscitados, deliberando sobre o sopesamento das normas de direito fundamental.

Posto isto, em se tratando das tutelas de urgência, como visto, é possível postergar o contraditório, onde é assegurado uma cognição exauriente, para deferimento de medidas cautelares ou antecipatórias por meio de cognição sumária, analisando os pressupostos típicos de cada medida, sem que isto cause prejuízo a parte, visto o caráter reversível das 


\section{tutelas de urgência, amparado no princípio da duração razoável do processo.}

\section{REFERÊNCIAS BIBLIOGRÁFICAS}

AMENDOEIRA Jr., Sidnei. Manual de Direito Processual Civil. Teoria geral do Processo e fase de conhecimento em primeiro grau de jurisdição. 2 ed. São Paulo: Saraiva. 2012.

BEDAQUE, José Roberto dos Santos. Direito e processo: influência do direito material sobre o processo. Tutela Cautelar e tutela antecipada: tutelas sumárias e de urgência São Paulo: Saraiva. 1998.

BONAVIDES, Paulo. Curso de Direito Constitucional. 26. Ed . São Paulo: Malheiros, 2011.

CANOTILHO, José Joaquim Gomes. Estudo sobre os Direitos Fundamentais. São Paulo: Saraiva. 2008.

CARNEIRO, Athos Gusmão. Da antecipação de tutela. 5ª ed. São Paulo: Saraiva. 2004.

CAVALCANTE FILHO, João trindade. Teoria geral dos direitos fundamentais.

Disponível:http://www.stf.jus.br/repositorio/cms/portalTvJustica/portalTvJusticaNoticia/anexo/Joao_ Trindadade_Teoria_Geral_dos_direitos_fundamentais.pdf .

CLÉVE, Clémerson Merlin. O Controle da Constitucionalidade e a Efetividade dos Direitos. São Paulo: Saraiva. 2005.

DIDIER JR., Fredie. Curso de direito processual civil. Ed. 12. Salvador: JusPodivm. 2007.

LAMY, Eduardo. Tutela Provisória, São Paulo: Atlas. 2018.

MELLO FILHO, José Celso. Constituição Federal anotada. 2. ed. São Paulo: Saraiva. 1986.

MENDES, Gilmar Ferreira; COELHO, Inocêncio Mártires; BRANCO, Paulo Gustavo Gonet. Curso de direito constitucional . 2. ed. . São Paulo: Saraiva. 2008.

MORAES, Alexandre de. Direito constitucional, 23ª Ed. 2. São Paulo: Atlas. 2008.

OLIVEIRA, Carlos Alberto Alvaro de. O processo civil na perspectiva dos Revista Intertemas. Leituras complementares de processo civil. 6. ed. Salvador: Juspodivm. 2008.

SARLET, Ingo Wolfgang. A eficácia dos direitos fundamentais- Porto Alegre: Livraria do Advogado. 1998.

ZAVASCKI, Teori Albino. Antecipação da tutela. São Paulo: Saraiva. 2000. 